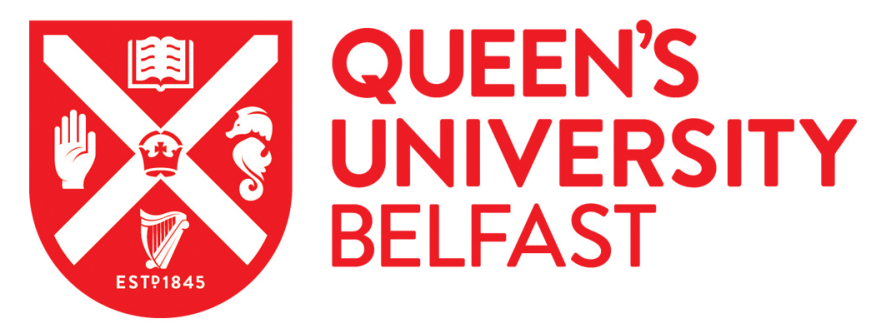

\title{
Halogen-bond mediated efficient storage of extremely volatile perfluoroiodides in ionic liquids
}

Gaspard, D., Seddon, K. R., Robertson, P. K. J., \& Gunaratne, H. Q. N. (2019). Halogen-bond mediated efficient storage of extremely volatile perfluoroiodides in ionic liquids. Chemical Communications.

https://doi.org/10.1039/C9CC04198B

\section{Published in:}

Chemical Communications

\section{Document Version:}

Peer reviewed version

Queen's University Belfast - Research Portal:

Link to publication record in Queen's University Belfast Research Portal

\section{Publisher rights}

(c) The Royal Society of Chemistry 2019. This work is made available online in accordance with the publisher's policies. Please refer to any applicable terms of use of the publisher.

\section{General rights}

Copyright for the publications made accessible via the Queen's University Belfast Research Portal is retained by the author(s) and / or other copyright owners and it is a condition of accessing these publications that users recognise and abide by the legal requirements associated with these rights.

Take down policy

The Research Portal is Queen's institutional repository that provides access to Queen's research output. Every effort has been made to ensure that content in the Research Portal does not infringe any person's rights, or applicable UK laws. If you discover content in the Research Portal that you believe breaches copyright or violates any law, please contact openaccess@qub.ac.uk. 


\title{
Chemical Communications
}

\section{COMMUNICATION}

\section{Halogen-bond mediated efficient storage of extremely volatile perfluoroiodides in ionic liquids}

Received 00th January 20xx, Accepted 00th January 20xx

\begin{abstract}
DOI: $10.1039 / \times 0 \times 00000 x$
\end{abstract}
www.rsc.org/

Highly volatile and valuable reagents, perfluoroiodides were shown to complex with ionic liquids with aid of a halogen-bond between a diverse set of anions and electrophilic iodine atom in perfluorinated iodides. The affinity of anions in various ionic liquids towards perfluoroiodides was examined by ${ }^{19} \mathrm{~F}$ NMR. Making use of the non-volatility of ionic liquids, we demonstrate here, perfluoroiodides can be stored and released controllably, on demand, from an ionic liquid matrix.

The capture and controlled release of substances play a vital part in the day to day life. Fluorinated organic molecules are increasingly useful in medicinal chemistry, agro chemistry, and materials science. ${ }^{1}$ Many recent advances in fluoroorganic chemistry ${ }^{2}$ are due to emerging reagents that are safer, less toxic with improved selectivity. The vast majority of perfluoroalkylating reagents reported in the literature are mainly trifluoromethylating reagents. They are structurally diverse in nature, including silicon containing agents, metallo-agents and completely organoreagents. ${ }^{3-8}$ Perfluoroalkyl iodides, in particular, $\mathrm{CF}_{3} \mathrm{l}$ and $\mathrm{CF}_{3} \mathrm{CF}_{2} \mathrm{l},{ }^{9}$ are useful but gaseous sources of perfluoroalkyl fragments. Consequently, handling gaseous or volatile compounds like $\mathrm{CF}_{3} \mathrm{l}, \mathrm{C}_{2} \mathrm{~F}_{5} \mathrm{I}, \mathrm{C}_{3} \mathrm{~F}_{7} \mathrm{I}$ and $\mathrm{C}_{4} \mathrm{~F}_{9} \mathrm{l}$ is cumbersome. Stock solutions of $\mathrm{CF}_{3} \mathrm{l}$ in conventional organic solvents cannot be stored without the quick decline of perfluorohalides over a period of time. The inherent volatility of common organic solvents and the lack of any form of 'conventional bonding' between the substrate and the solvent add further difficulties in working with these materials. Very recently, super basic amines such as teramethylguanidines have been shown to complex perfluoroiodides efficiently via halogen-bonding, ${ }^{10}$ though long-term storage of such iodides in strongly basic materials may lead to undesirable side-reactions. Furthermore, these amines also possess some volatility. Increasingly, halogen bonding ${ }^{11}$ has been shown to facilitate the assembly of diverse hosts and guests,

\footnotetext{
a. The QUILL Research Centre, School of Chemistry and Chemical Engineering, Queen's University Belfast.

b.School of Chemistry and Chemical Engineering, Queen's University Belfast, Stranmillis Road, Belfast BT9 5AG, UK.

Ecole Supérieure de Chimie Organique et Minérale (Escom), Paris.

+ E-mail: n.qunaratne@qub.ac.uk

${ }^{d}$ Deceased
}

leading to some applications. In a recent publication, it was shown that quaternary ammonium iodides were able to resolve mixtures of perfluorodiiodides and mediated by halogen-bonding. ${ }^{12}$

In this respect, appropriately designed ionic liquids have been given scant attention in their utilisation in capturing and delivering materials such as perfumes ${ }^{13}$ and expensive fluorinating agents. There is an example in the literature describing the capture of trifluoromethane mediated by ionic liquids. ${ }^{14}$ The forces of attraction of such compounds towards ionic liquids are, however, likely to be weak and elusory in nature. Chloride containing ionic liquids were shown, recently, to capture $\mathrm{Cl}_{2}$ gas forming $\mathrm{Cl}_{3}$ anion via covalent bonding. ${ }^{15}$ In this respect, it would be desirable to have appropriately designed ionic liquids targeting specific bonding to parts of a compound, without affecting their integrity to store and deliver volatile perfluoro compounds on demand. Such a concept is illustrated in Figure 1.

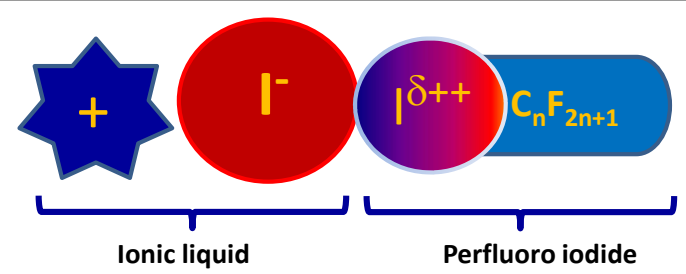

Figure 1: An illustration to show a possible binding mode involving a halogen bond for an 'iodide' ionic liquid interacting with a perfluoro iodide.

In this communication, we describe a set of carefully chosen ionic liquids (see Scheme 1) bearing a set of diverse anions, in particular, iodide anions where the cations are chosen in order to

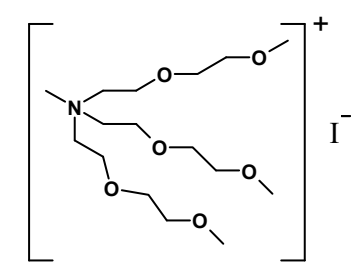

(1)

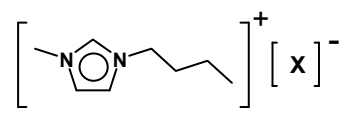

(2) $\mathrm{X}=\mathrm{CF}_{3} \mathrm{SO}_{3}, \mathrm{MeOSO}_{3}, \mathrm{~N}(\mathrm{CN})_{2}, \mathrm{CF}_{3} \mathrm{CO}_{2}$ $\mathrm{SCN},(\mathrm{MeO})_{2} \mathrm{PO}_{2}, \mathrm{I}, \mathrm{Br}, \mathrm{Cl}, \mathrm{OAc}, \mathrm{NTf}_{2}$ $\mathrm{NTf}_{2}=$ bis(trifluoromethanesulfonyl)imide

Scheme 1: Ionic liquids with diverse anions that are used in this study. 
minimise cation-halide interactions yet maintaining maximum fluidity. Some of these ionic liquids are low melting solids (melting points $<70^{\circ} \mathrm{C}$ ). Syntheses of all the ionic liquids, given in scheme 1, were fairly straightforward and they were characterised by standard analytical techniques. (1) is a room temperature ionic liquid $\left(T_{g}=-62.3{ }^{\circ} \mathrm{C}\right)$, except [bmim] chloride, bromide and iodide all others were liquids at room temperature.

All ionic liquids described in Scheme 1 were allowed interact with, initially, $\mathrm{C}_{4} \mathrm{~F}_{9} \mathrm{l}$ in the neat state (mole ratio; $\mathrm{IL}: \mathrm{C}_{4} \mathrm{~F}_{9} \mathrm{I}=1.2: 1$ ) and then analysed by ${ }^{19} \mathrm{~F}$ NMR spectroscopy. Two such examples of ${ }^{19} \mathrm{~F}$ NMR spectra of (1) and [bmim] I with $\mathrm{C}_{4} \mathrm{~F}_{9} \mathrm{l}$ are given in Figure 2. The interaction of electrophilic iodine atom in $\mathrm{C}_{4} \mathrm{~F}_{9} \mathrm{l}$ with the anions of two ionic liquids can be seen by the large shift of ${ }^{19} \mathrm{~F}$ signal corresponds to- $\mathrm{CF}_{2} \mathrm{-l}$; with (1) $\Delta \delta$ of 13.1 and with [bmim] $\Delta \delta$ of 10.4 was observed.
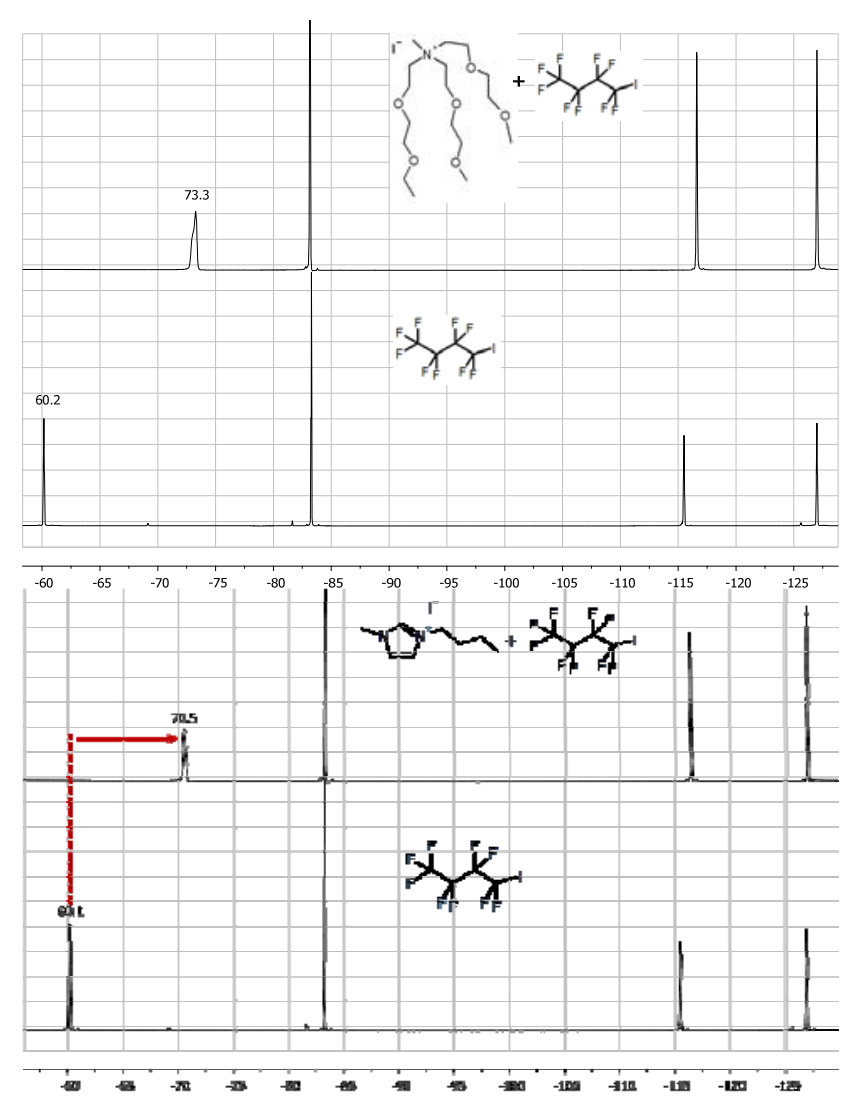

Figure 2: Partial ${ }^{19} \mathrm{~F}$ nmr spectra of Top: a mixture of $\mathrm{C}_{4} \mathrm{~F}_{9}$ l and [bmim] l; bottom: a mixture of $\mathrm{C}_{4} \mathrm{~F}_{9} \mathrm{I}$ and ionic liquid, 1.

These chemical shift changes are significantly high indicating the strong halogen bonding interactions between iodide anion in both ionic liquids and the perfluoroiodide. Higher polarisability of the iodide, ${ }^{16}$ hence, its ability to donate electrons easily towards more electrophilic centres is well documented and probably, accounts for its ability to form stronger halogen bonds. Armed with these initial findings, we carried out a comprehensive ${ }^{19} \mathrm{~F}$ nmr study with a broad range of ionic liquids carrying a diverse collection of anions. The results are given in figure 3 . The vast majority of the cations were 1-butyl-3-methylimidazolium (bmim) except for cations present in ionic liquid 11 and 14 (these numbers refer to Fig. 3); viz methyl-tris[2-(2- methoxyethoxy)ethyl]ammonium].

\begin{tabular}{|l|l|l|l|}
\hline & 13 \\
\hline
\end{tabular}

Figure 3: Partial ${ }^{19} \mathrm{~F}$ NMR spectra of mixtures of $\mathrm{C}_{4} \mathrm{~F}_{9}$ l and ionic liquids $[\mathbf{C}]^{+}[\mathbf{X}]^{-}$where $\mathrm{C}=$ 1-butyl-3-methylimidazolium (bmim) for 2-10,12,13; C=

methyltris [2-(2-methoxyethoxy)ethyl]ammonium for 11, 14; The anion [X]- in 2, $\mathrm{CF}_{3} \mathrm{SO}_{3}$; 3, $\mathrm{MeOSO}_{3} ; 4, \mathrm{~N}(\mathrm{CN})_{2} ; 5, \mathrm{CF}_{3} \mathrm{CO}_{2} ; 6, \mathrm{SCN} ; 7,(\mathrm{MeO})_{2} \mathrm{PO}_{2} ; 8, \mathrm{I} ; \mathbf{9}, \mathrm{Br} ; 10, \mathrm{Cl} ; 1$, neat $\mathrm{C}_{4} \mathrm{~F}_{9} \mathrm{I}$. In all cases, ${ }^{19} \mathrm{~F}$ NMR spectra were run with a dmso- $d_{6}$ external lock.

All the nmr spectra shown in figure 3 were recorded on mixtures of neat ionic liquids and neat $\mathrm{C}_{4} \mathrm{~F}_{9}$ l with a sealed capillary filled with dmso- $d_{6}$ as an external lock. As expected, anions such as $\mathrm{CF}_{3} \mathrm{SO}_{3}{ }^{-}$and $\mathrm{CH}_{3} \mathrm{SO}_{3}{ }^{-}$formed weaker interaction with $\mathrm{C}_{4} \mathrm{~F}_{9}$ l due to their charge distribution leading to low charge densities on oxygens. Unsurprisingly, halide anions and acetate anion showed a higher affinity towards halogen bonding to perfluoroiodide. This may be due to better orbital energy matching and overlap with such anions. It is noteworthy that the $\mathrm{H}$-bonding affinity with some of these anions are strongly related, albeit indirectly, to the ability to dissolve cellulose. ${ }^{17}$

$\Delta \delta$ shifts of $-\mathrm{CF}_{2}-\mathrm{I}$ in $\mathrm{C}_{4} \mathrm{~F}_{9} \mathrm{I}[\mathrm{bmim}][\mathrm{X}]$

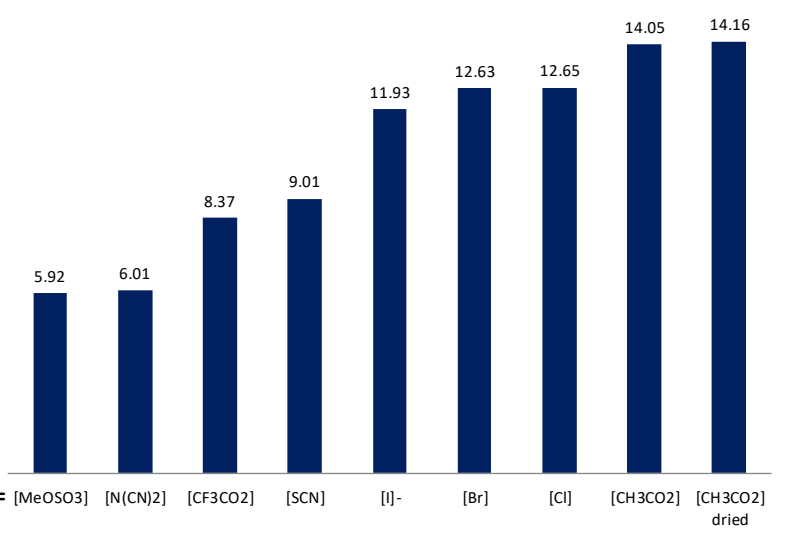

Figure 4: $\mathrm{A}$ histogram of ${ }^{19} \mathrm{~F}$ NMR chemical shift changes, $\Delta \delta$, of the $-\mathrm{CF}_{2}-\mathrm{I}$ group in $\mathrm{C}_{4} \mathrm{~F}_{9} \mathrm{I}$ in $[\mathrm{bmim}][\mathrm{X}]$ where $\mathrm{X}=\mathrm{MeOSO}_{3} ; \mathrm{N}(\mathrm{CN})_{2} ; \mathrm{CF}_{3} \mathrm{CO}_{2} ; \mathrm{SCN} ; \mathrm{I} ; \mathrm{Br} ; \mathrm{Cl} ; \mathrm{CH}_{3} \mathrm{CO}_{2}$. N.B.

[bmim] $\left[\mathrm{NTf}_{2}\right.$ ] was eliminated from the study due to its phase separation with $\mathrm{C}_{4} \mathrm{~F}_{9}$ I 
The histogram shown in figure 4 gives an indicative synopsis of the $\Delta \delta$ values for different anions interacting with $\mathrm{C}_{4} \mathrm{~F}_{9}$ l. All cations associated with these anions were kept constant which is $[\mathrm{bmim}]^{+}$. Acetate appears to lend the largest $\Delta \delta$ while all halide anions impart similarly large $\Delta \delta$ changes. As the negative charge on acetate is equally shared between two oxygen atoms, it provides the opportunity to form bifurcated halogen bonds ${ }^{18}$ with electrophilic iodine atom. This may account for acetate displaying a stronger interaction. Furthermore, the presence of trace amounts of water in [bmim] [OAc] does not appear to have a significant effect on the $\Delta \delta$, as can be evidenced from the last two columns on the right, in figure 4. Moreover, halogen bonding originating from halide to halogen is relatively common whereas halogen bonding to other negatively charged or electron rich atoms is less common. ${ }^{19}$ According to the findings summarised in figure 4 , the weakest interactions were found with methylsulfate and dicyanamide anions. This could be attributed to negative charge distribution in such anions among many atoms.

Next, we focussed our attention to the controlled release of $\mathrm{C}_{4} \mathrm{~F}_{9} \mathrm{l}$ from ionic liquid matrixes under thermal conditions. An initial experiment was performed, with an IL/ $\mathrm{C}_{4} \mathrm{~F}_{9}$ l mixture having a molar ratio of (1): $\mathrm{C}_{4} \mathrm{~F}_{9} \mathrm{l}=1.2: 1$, within a Thermogravimetric Analysis (TGA) instrument. Static conditions at $25{ }^{\circ} \mathrm{C}$ with a nitrogen flow of $1 \mathrm{ml} \mathrm{m}^{-1}$ was maintained throughout the experiment. A blank experiment was also performed just with $\mathrm{C}_{4} \mathrm{~F}_{9} \mathrm{l}$ without the ionic liquid under identical conditions. The results are given in figure 5 showing the swift disappearance $(<4 \mathrm{~m}$; red line) of the perfluoroiodide in the absence of the ionic liquid whereas the (1) is able to retain $\mathrm{C}_{4} \mathrm{~F}_{9} \mathrm{l}$ for $150 \mathrm{~m}$ (navy blue line).
Consequently, a series of experiments were performed, in an apparatus shown in ESI-figure S2, with ten ionic liquids where $\mathrm{C}_{4} \mathrm{~F}_{9} \mathrm{l}$ was dissolved maintaining the same molar ratio as before. All experiments were performed at $40^{\circ} \mathrm{C}$ and the

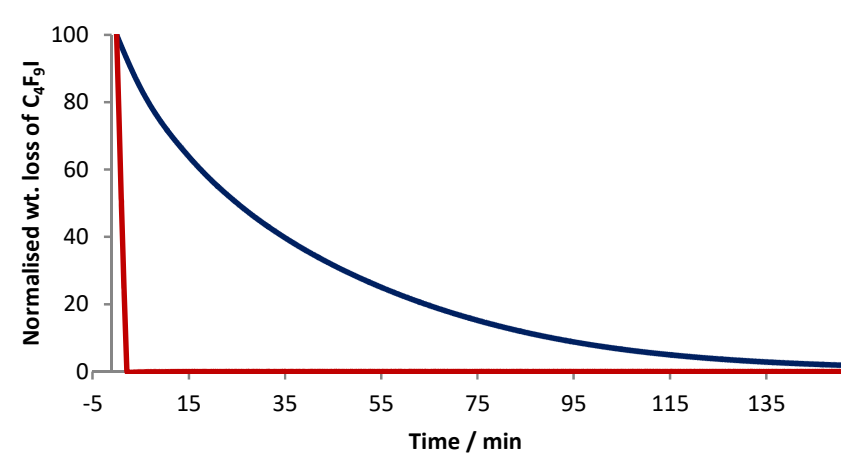

Figure 5: A plot of normalised weight loss against time for $\mathrm{C}_{4} \mathrm{~F}_{9} \mathrm{l}(\mathrm{a})$, Red in the absence of any ionic liquid, (b) Navy blue, in the presence of ionic liquid (5). The molar ratio of $\mathrm{IL}: \mathrm{C}_{4} \mathrm{~F}_{9} \mathrm{I}=1.2: 1$ and the plots were obtained using static thermogravimetric analysis (TGA) in a TGA instrument at $25^{\circ} \mathrm{C}$, with a nitrogen flow of $1 \mathrm{ml} \mathrm{m}^{-1}$.

release of $\mathrm{C}_{4} \mathrm{~F}_{9}$ l were monitored with time, gravimetrically, without $\mathrm{N}_{2}$ flowing over the sample. The kinetic profiles of the release of $\mathrm{C}_{4} \mathrm{~F}_{9}$ l for all experiments are given in figure 6 . There is a cluster of six lines congregating at the top which are all halide containing ionic liquids, except $[$ bmim $]\left[\mathrm{CH}_{3} \mathrm{CO}_{2}\right]$, binding tightly to the perfluoroiodide with stronger halogen bonding. $[\mathrm{Bmim}]\left[\mathrm{CF}_{3} \mathrm{CO}_{2}\right]$ and $[\mathrm{bmim}]\left[\mathrm{CF}_{3} \mathrm{SO}_{3}\right]$ appears to have the weakest hold on the perfluoroiodide. The weaker donor ability

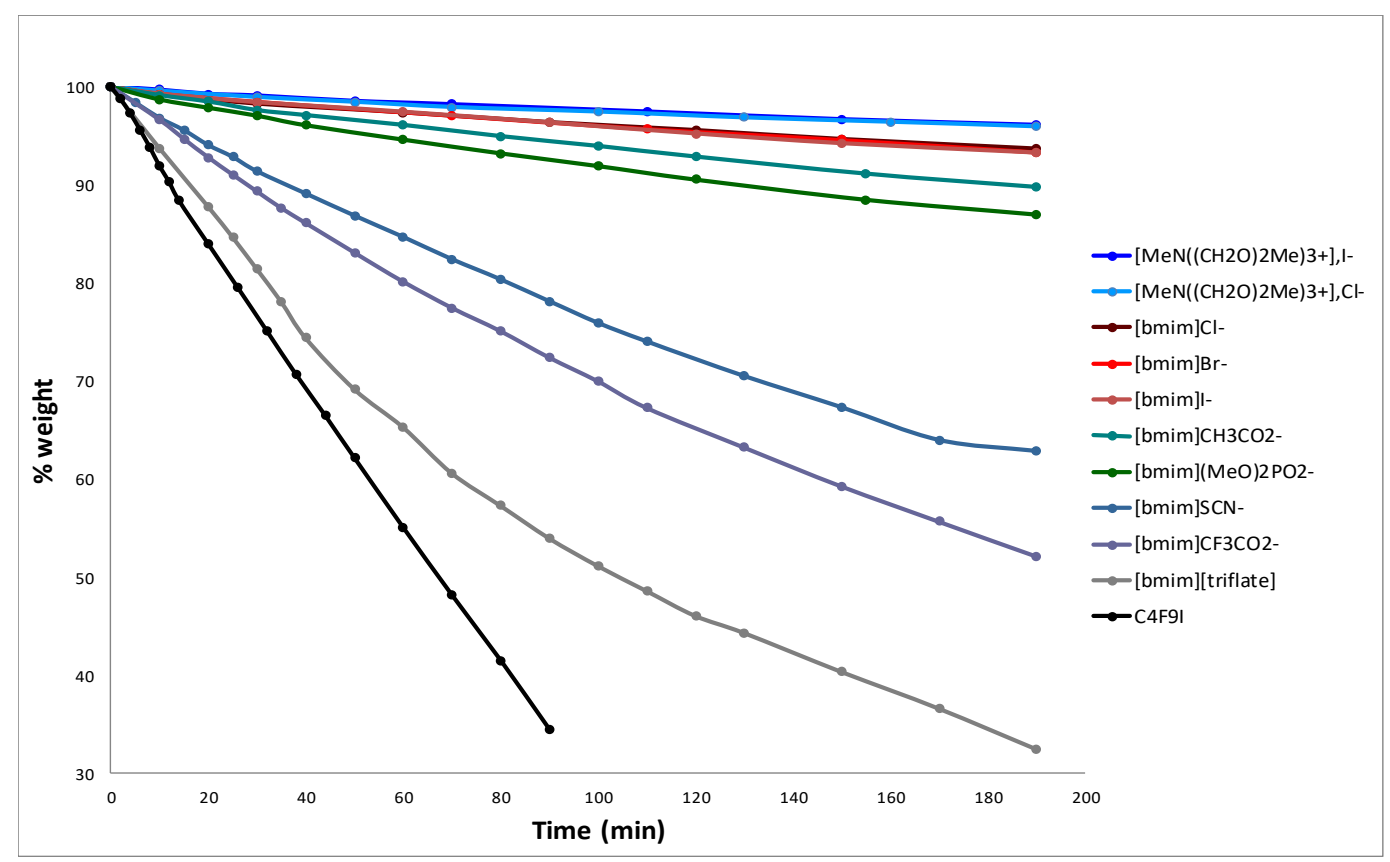

Figure 6: Release profiles of perfluoroiodobutane from a set of ionic liquids with diverse anions, performed at $40{ }^{\circ} \mathrm{C}$ in an apparatus shown in figure $\mathrm{S} 2$ in ESI. In all cases the molar ratio of ionic liquid: $\mathrm{C}_{4} \mathrm{~F}_{9} \mathrm{l}=1.2: 1.0$. The weight loss (as a percentage) was measured gravimetrically using a four-figure balance. 


\section{Chemical Communications}

\section{COMMUNICATION}

of fluorinated anions is well known which could account for this observation. The viscosity of ionic liquids, however, may also play a role in affecting the mass transport of such volatile materials embedded in their domain. Therefore, apart from halogen bonding interactions, the contribution emanating from the viscosity of the matrix cannot be discounted in the delivery process.

In conclusion, we have described here the versatility of some ionic liquids to be utilised as storage media or 'surrogates' for volatile, expensive and commonly used perfluoroiodides without affecting the integrity of these reagents. We have used ${ }^{19} \mathrm{~F}$ NMR effectively to investigate the degree of interaction between perfluoro-reagents and ionic liquids. It is also demonstrated how these materials could be released in a controllable manner, on demand, by virtue of gentle heat. These reagents can be stored, at room temperature, in suitable ionic liquids for months without any significant material loss.

The authors wish to thank Richard Murphy for assistance with NMR spectra, Angela Brownlee for TGA and DSC and George Burton for designing and constructing the glass apparatus that was used for experiments involving releasing perfluoroiodide. HQNG acknowledges the constant support and encouragement given to him by the late co-author, Prof. Kenneth R. Seddon.

\section{Conflicts of interest}

There are no conflicts to declare.

\section{Notes and references}

\# Electronic Supplementary Information (ESI) available: additional NMR data, UV-Vis. Spectra, DSC and TGA of new ionic liquids and details of the apparatus used in the work are given in ESI. See DOI: 10.1039/x0xx00000x.

1 C. Ni and J. Hu, Chem. Soc. Rev., 2016, 45, 5441; E. P. Gillis, K. J. Eastman, M. D. Hill, D. J. Donnelly and N. A. Meanwell, J. Med. Chem., 2015, 58, 8315-8359; T. Furuya, A. S. Kamlet, T. Ritter, Nature, 2011, 473, 470-477; C. Hollingworth, V. Gouverneur, Chem. Commun. 2012, 48, 2929-2942; T. Liang, C. N. Neumann, T. Ritter, Angew. Chem. Int. Ed. 2013, 52, 8214 - 8264; Angew. Chem. 2013, 125, 8372 - 8423; M. G. Campbell, T. Ritter, Org. Process Res. Dev., 2014, 18, 474480; R. Wilcken, M. O. Zimmermann, A. Lange, A. C. Joerger and F. M. Boeckler, J. Med. Chem., 2013, 56, 1363-1388.

2 Z. Jin, G. B. Hammond and B. Xu, Aldrichimica Acta, 2012, 45, 67-83; Modern Fluoroorganic Chemistry (Ed.: P. Kirsch), Wiley-VCH, Weinheim, 2004; Current Fluoroorganic Chemistry, Copyright, Foreword, Current Fluoroorganic Chemistry. January 11, 2007, i-v, ACS Symposium Series.

3 I. Ruppert, K. Schlich, W. Volbach, Tetrahedron Lett., 1984, 25, 2195-2198; G. K. S. Prakash, R. Krishnamurti, G. A. Olah,
J. Am. Chem. Soc., 1989, 111, 393-395; G. K. S. Prakash, A. K. Yudin, Chem. Rev., 1997, 97, 757-786.

4 H. Morimoto, T. Tsubogo, N. D. Litvinas and J. F. Hartwig, Angew. Chem. Int. Ed., 2011, 50, 3793-3798; Angew. Chem. 2011, 123, 3877-3882.

5 B. R. Langlois, E. Laurent, N. Roidot, Tetrahedron Lett., 1991, 32, 7525-7528.

6 Y. Fujiwara, J. A. Dixon, R. A. Rodriguez, R. D. Baxter, D. D. Dixon, M. R. Collins, D. G. Blackmond and P. S. Baran, J. Am. Chem.Soc., 2012, 134, 1494-1497

7 T. Umemoto, Chem. Rev., 1996, 96, 1757-1777; T. Umemoto, K. Adachi, S. Ishihara, J. Org. Chem., 2007, 72, 6905-6917; J. Xu, Y. Fu, D.-F. Luo, Y.-Y. Jiang, B. Xiao, Z.-J. Liu, T.-J. Gong and L. Liu, J. Am. Chem. Soc., 2011, 133, 15300-15303.

8 P. Eisenberger, I. Kieltsch, R. Koller, K. Stanek and A. Togni, Org. Synth. 2011, 88, 168-180; V. Matousek, E. Pietrasiak, R. Schwenk and A. Togni, J. Org. Chem., 2013, 78, 6763-6768.

9 M. T. Kino, Y. Nagase, Y. Ohtsuka, K. Yamamoto, D. Uraguchi, K. Tokuhisa, T. Yamakawa, J. Fluorine Chem., 2010, 131, 98105; J. D. Nguyen, J. W. Tucker, M. D. Konieczynska, C. R. J. Stephenson, J. Am. Chem. Soc., 2011, 133, 4160-4163; C.-J. Wallentin, J. D. Nguyen, P. Finkbeiner and C. R. J. Stephenson, J. Am. Chem. Soc., 2012, 134, 8875-8884.

10 F. Sladojevich, E. McNeill, J. Bçrgel, S.-L. Zheng, and T. Ritter, Angew. Chem. Int. Ed., 2015, 54, 3712-3716.

11 Gabriella Cavallo, P. Metrangolo, R. Milani, T. Pilati and A. Priimagi, G. Resnati and G. Terraneo, Chem. Rev., 2016, 116, 2478-2601; G. Cavallo, G. Terraneo, A. Monfredini, M. Saccone, A. Priimagi, T. Pilati, G. Resnati, P.Metrangolo, and D. W. Bruce, Angew. Chem. Int. Ed., 2016, 55, 6300-6304; P. Metrangolo, F. Meyer, T. Pilati, G. Resnati and G. Terraneo Angew. Chem. Int. Ed., 2008, 47, 6114-6127.

12 P. Metrangolo, Y. Carcenac, M. Lahtinen, T. Pilati, K. Rissanen, A. Vij and G. Resnati, Science, 2009, 323, 14611464.

13 F. M. Ferrero Vallana, R. P. Girling, H. Q. N. Gunaratne, L. A. M. Holland, P. M. Mcnamee, K. R. Seddon, J. R. Stonehouse and O. Todini, New J. Chem., 2016, 40, 9958-9967; H. Q. N. Gunaratne, P. McCarron and K. R. Seddon, Green Chem., 2017, 19, 614-618.

14 M. B. Shiflett, US Patent, 2015, US 2015/0082981 A1; M. B. Shiflett, D. R. Corbin, B. A. Elliott and A. Yokozeki, J. Chem. Thermodynamics, 2013, 64, 40-49

15 X. Li, A. Van den Bossche, T. V. Hoogerstraete and K. Binnemans, Chem. Commun., 2018, 54, 475-478.

16 E. Bichoutskaia and N. C. Pyper, J. Phys. Chem. C, 2007, 111, 9548-9561;

17 A. Pinkert, K. N. Marsh, S. Pang and M. P. Staiger, Chem. Rev., 2009, 109, 6712-6728; R. Rinaldi, Chem. Commun., 2011, 47, 511-513; B. Zhao, L. Greiner and W. Leitner, RSC Advances, 2012, 2, 2476-2479.

18 M. Novak, C. Foroutan-Nejad and R. Marek, Phys. Chem. Chem. Phys., 2015, 17, 6440-6450; V. Stilinovic, T. Grguric, T. Pitesa, V. Nemec and D. Cincic, Cryst. Growth Des., 2019, 19, $1245-1256$

19 A. Brown and P. D. Beer, Chem. Commun., 2016, 52, 86458658. 